\title{
Load Displacement Behavior of the Human Lumbo-sacral Joint
}

\author{
K. M. McGlashen, J. A. A. Miller, A. B. Schultz, ${ }^{*}$ G. B. J. Andersson, \\ Department of Mechanical Engineering and Applied Mechanics, University of Michigan, Ann Arbor, Michigan; and \\ *Department of Orthopedic Surgery, St. Lukes-Rush-Presbyterian Hospital, Chicago, Illinois, U.S.A.
}

\begin{abstract}
Summary: The three-dimensional load displacement behavior of nine fresh adult L5-S1 spine motion segments was studied. Static test forces up to $160 \mathrm{~N}$ in anterior, posterior, and lateral shear, test forces up to $320 \mathrm{~N}$ in compression, and test moments up to $15.7 \mathrm{Nm}$ in flexion, extension, lateral bending, and torsion were used. The six displacements of the center of the inferior L5 endplate were measured 15 and $60 \mathrm{~s}$ after the load was applied. Specimens were then retested after posterior element excision. The results show that at the maximum test force, intact specimen mean (SD) displacements ranged from $1.65 \mathrm{~mm}(0.63 \mathrm{~mm})$ in lateral shear to $2.21 \mathrm{~mm}(0.87 \mathrm{~mm})$ in posterior shear. Posterior element excision resulted in an average 1.66-fold increase in shear translations. At the maximum moment, rotations ranged from $3.38^{\circ}\left(1.03^{\circ}\right)$ in torsion to $7.19^{\circ}\left(1.77^{\circ}\right)$ in flexion. Posterior element excision resulted in an average 2.09-fold increase in bending rotations and a 2.74-fold increase in the average torsional rotation. In general, these L5-S1 joints were stiffer than more cranial lumbar segments in flexion, extension, and lateral bending and were less stiff in torsion tests. Key Words: Lumbo-sacral joint-Lumbar spine-Stiffness-Apophyseal joints-Mechanical properties.
\end{abstract}

Low back pain and sciatica are among the most common musculoskeletal complaints in the population $(8,26,28,29)$. A frequent location of lumbar spine pathology is the lumbo-sacral (L5-S1) junction (27) whose pathologies include disk herniation $(1,3,23)$, spondylolysis $(6,23)$, and spondylolisthesis $(3,23,30)$.

Mechanical factors have been believed to explain the frequency of lumbar spine pathologies at the L5-S1 level. Both experimental studies (16) and computer simulations (25) show that large loads are placed on the lumbar spine by daily activities. In addition, radiological studies have shown that the L5-S1 spine segment must carry these loads through one of the largest ranges of motion (ROM)

Address correspondence and reprint requests to Dr. J. A. Ashton-Miller at 3208 G. G. Brown Laboratory, Department of Mechanical Engineering and Applied Mechanics, University of Michigan, Ann Arbor, Michigan 48109, U.S.A. in the thoracic or lumbar spine, for example, up to $10^{\circ}$ in flexion $(7,20,21)$.

For a better estimate of the stresses placed on the L5-S1 joint and its substructures during a given activity, its load displacement behavior should be known. Many previous investigations have studied the mechanical behavior of lumbar spine segments $(4,9-12,17,18,22,24)$. One study included the load displacement response of the L5-S1 joint for loads restricted to the sagittal plane (22). No comprehensive data on the three-dimensional behavior of the L5-S1 joint are available, however. The purpose of this article, therefore, is to present the three-dimensional load displacement behavior of fresh adult L5-S1 joints.

\section{METHODS}

Intact L5-S1 specimens were excised from nine fresh cadavers aged 55 years or older. All interver- 
tebral ligaments and joints were left intact, but the ilio-lumbar ligaments were sectioned bilaterally. One specimen had an osteophyte connecting the superior and inferior vertebral bodies on the anterior margin of the disc. The other specimens showed no radiographic abnormalities. The specimens were sealed and stored at $-20^{\circ} \mathrm{C}$ until just before testing. The anteroposterior and lateral disc diameters of each segment were measured with dial calipers $(0.01 \mathrm{~mm})$. Mean (SD) anteroposterior and lateral disc diameters were $37.76 \mathrm{~mm}(3.5 \mathrm{~mm})$ and $64.38 \mathrm{~mm}(6.5 \mathrm{~mm})$, respectively.

At the time of testing, specimens were thawed for mounting in the test apparatus. The sacrum was sectioned in the transverse plane $5 \mathrm{~cm}$ below the disc. The L5 transverse processes, together with their intertransverse ligaments, were removed to allow mounting in the fixture plate. To enable rigid gripping of the specimen at the intended loads, muscle, fat, and other soft tissues were removed from the vertebral endplates and cortical surfaces to within $1 \mathrm{~cm}$ of the disc margins. The specimen was then clamped to the test apparatus fixture plates by passing multistrand steel wires over each pedicle and through the spinous process and drawing the wires tight. Wood screws were partially inserted into the vertebral and sacral cortical bone. The superior two-thirds of the L5 vertebra and the inferior $4 \mathrm{~cm}$ of the sacrum were each mounted in the fixtures with acrylic cement. With the wires and screws firmly anchoring the specimen in the cement, a rigid fixation was obtained (Fig. 1). Care was taken not to disturb the motion segment tissues outside the region used for gripping. Damp cloths were wrapped around the mounted specimen to maintain its moisture content.

The methods and apparatus used for applying loads and measuring motions were similar to those used by Berkson and colleagues (4) (see Discussion section). In this study, static shear forces and moments, the latter using pure couples, were applied in increments to the geometric center $(0)$ of the inferior L5 endplate through a system of cables and pneumatic cylinders; S1 was rigidly fixed to the bed of the testing apparatus with the inferior endplate of L5 mounted horizontally (Fig. 1). Because the loading cables were both long and flexible, they supplied negligible resistance to L5 motions. To minimize the effect of the "neutral zone" (19) on results, a small bias load less than the first load increment was applied in the direction of loading and removed. Four equal static load increments were then applied at 60 -s intervals in each of the eight test directions. The same series of tests was performed for all specimens in a predetermined order: axial compression, left lateral shear, axial torsion (counterclockwise when viewed from above), flexion, extension, anterior shear, right lateral bending, and posterior shear. Maximum loads of $160 \mathrm{~N}$ in shear, $320 \mathrm{~N}$ in compression, and 15.68 $\mathrm{Nm}$ in bending and torsion were applied.

Displacements and rotations of the L5 vertebral

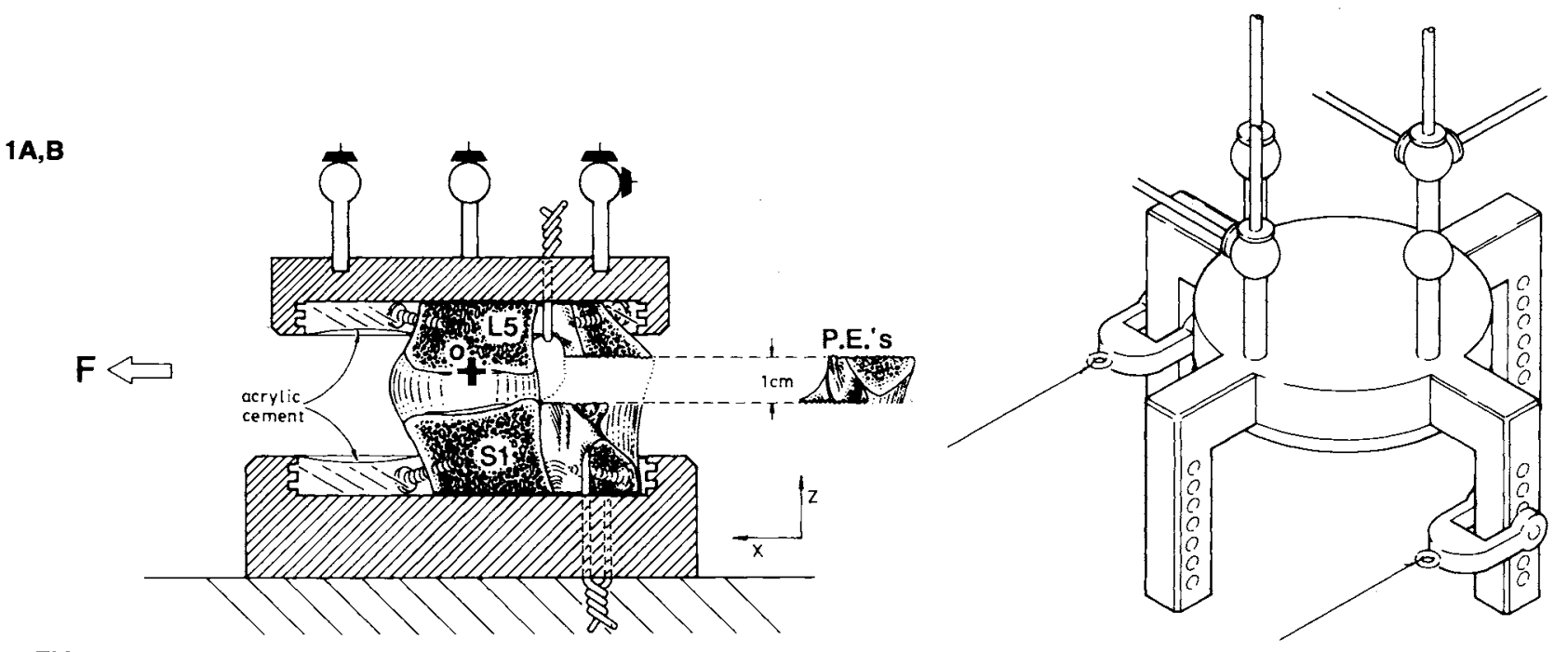

FIG. 1. A: Lateral view of a midsagittal section through a mounted specimen. To facilitate rigid fixation in acrylic cement, wood screws were partially inserted into cortical bone, and multistrand steel wires were passed over pedicles and through spinous processes, then tightened from their respective mounting plates. B: Schematic diagram shows how test loads were applied through $\mathrm{O}$ using two cables and placement of the six displacement transducers. 
body were measured in three orthogonal planes using six linear variable differential transformers (LVDTs). The LVDTs were positioned to contact three steel balls attached to the upper fixture plate (Fig. 1). Voltages from each LVDT were sampled 15 and $60 \mathrm{~s}$ after each load increment was applied. From these measurements and from knowledge of the fixture geometry and the height of the fixture above $O$ (measured with dial calipers), the three translations and three rotations of $O$ relative to its unloaded initial position were calculated to the nearest $0.5 \mathrm{~mm}$ and $0.25^{\circ}$ using rigid body kinematic theory. If rotations approached $10^{\circ}$ at the third load increment in bending tests, the fourth and final load increment was not applied to avoid specimen damage; instead results for the fourth load increment were linearly extrapolated from the second and third load increment results (Table 1).

Creep was estimated by expressing displacements at $15 \mathrm{~s}$ as a percentage of the 60-s displacements. To measure specimen hysteresis, three-dimensional displacements were measured $60 \mathrm{~s}$ after maximum load removal and expressed as a percentage of maximum displacements.

The experiments were then repeated after the posterior elements (consisting of facet joints, the interspinous ligament, and the ligamentum flavum) were removed. To prevent their limiting motions in extension and lateral bending, these structures were removed for a total height of $\sim 1 \mathrm{~cm}$ (Fig. 1). Four specimens failed in flexion before the fourth load increment could be applied, one before any data could be gathered. These were not used in fur- ther testing. When possible, flexion displacements at maximum load were extrapolated nonlinearly, based on the mean load displacement behavior of the remaining segments.

Stiffness in a given mode of loading was defined as the maximum load applied divided by the translation or rotation of $O$ in that direction at that load. In matrix notation, this definition of secant stiffness is equivalent to the inverse of the flexibility coefficient. To estimate the effect of removing the "neutral zone" or low-load nonlinear behavior (19), the "tangent" stiffness from the first to the maximum load was also calculated.

Three specimens without posterior elements were also used to study the effect of a compressive preload on measured load displacement behavior using the standard four test load increments. One specimen was preloaded to $640 \mathrm{~N}$ and retested in torsion, and the remaining two specimens were preloaded to $320 \mathrm{~N}$ and retested in left lateral shear.

To compare the present shear data with earlier shear data obtained with an added bending component $(4,24)$, the effect of raising the point of load application $5.3 \mathrm{~cm}$ was studied in two specimens without posterior elements in lateral shear. After testing was complete, the disc degeneration state was evaluated by visual inspection (15) (Table 2).

Repeatability of test procedures was determined from three specimens tested twice in a single test direction. The averaged SE was calculated from displacements at the same load and expressed as a percentage of the mean displacement for all specimens at that load. The paired Student's $t$ test was

TABLE 1. Range of motion data

\begin{tabular}{|c|c|c|c|c|c|c|c|c|c|}
\hline \multirow[b]{2}{*}{ Load direction } & \multirow[b]{2}{*}{ Load } & \multirow[b]{2}{*}{$\mathbf{N}$} & \multicolumn{2}{|c|}{ Posterior elements intact } & \multirow[b]{2}{*}{$\mathbf{N}$} & \multicolumn{2}{|c|}{ Without posterior elements } & \multirow{2}{*}{$\begin{array}{c}\text { Ratio: } \\
\text { without PE/ } \\
\text { PE intact }\end{array}$} & \multirow{2}{*}{$\begin{array}{c}\mathrm{P} \\
\text { value }\end{array}$} \\
\hline & & & Mean (SD) & Range & & Mean (SD) & Range & & \\
\hline Compression & $320 \mathrm{~N}$ & 9 & $0.32(0.16)$ & $0.18-0.66$ & 8 & $0.51(0.33)$ & $0.19-1.13$ & 1.59 & NS \\
\hline Lateral shear & $160 N$ & 8 & $1.65(0.63)$ & $1.02-2.66$ & 8 & $2.14(0.84)$ & $1.03-3.99$ & 1.30 & NS \\
\hline Anterior shear & $160 \mathrm{~N}$ & 7 & $2.05(1.39)$ & $0.93-5.06$ & 7 & $4.26(2.52)$ & $1.75-8.73$ & 2.08 & $<0.05$ \\
\hline Posterior shear & $160 \mathrm{~N}$ & 8 & $2.21(0.87)$ & $0.98-3.85$ & 7 & $3.54(0.81)$ & $2.55-4.43$ & 1.60 & $<0.05$ \\
\hline Torsion & $15.7 \mathrm{~nm}$ & 9 & $3.38(1.03)$ & $2.00-5.27$ & 8 & $9.27(3.23)$ & $4.46-14.40$ & 2.74 & $<0.05$ \\
\hline Flexion & $15.7 \mathrm{~nm}$ & 9 & $7.19(1.77)$ & $4.68-10.01^{a}$ & 6 & $18.51(8.47)$ & $7.11-30.29^{b}$ & 2.57 & $<0.05$ \\
\hline Extension & $15.7 \mathrm{~nm}$ & 9 & $5.16(1.28)$ & $3.77-7.46^{c}$ & 7 & $9.67(3.20)$ & $6.31-13.71$ & 1.87 & $<0.01$ \\
\hline \multicolumn{10}{|l|}{ Right lateral } \\
\hline bending & $15.7 \mathrm{~nm}$ & 8 & $4.38(1.44)$ & $3.02-6.52$ & 6 & $6.83(1.75)$ & $4.09-8.75$ & 1.56 & NS \\
\hline
\end{tabular}

Displacements were measured at the center of the inferior endplate of the L5 vertebral body. Units are millimeters (shear and compression tests) or degrees (torsion and bending tests).

NS, not significant; $P E$, posterior elements.

a Extrapolated specimen nos. 5, 6, 8, and 9.

b Extrapolated specimen nos. 2, 4, 7, 8, and 9.

c Extrapolated specimen no. 6. 
TABLE 2. Geometric properties of L5-S1 motion segments used in this study

\begin{tabular}{cccccc}
\hline & & & \multicolumn{2}{c}{ Disc height } & \\
$\begin{array}{c}\text { Specimen } \\
\text { no. }\end{array}$ & $\begin{array}{c}\text { Lateral } \\
\text { diameter } \\
(\mathrm{mm})\end{array}$ & $\begin{array}{c}\text { Sagittal } \\
\text { diameter } \\
(\mathrm{mm})\end{array}$ & $\begin{array}{c}\text { Anterior } \\
(\mathrm{mm})\end{array}$ & $\begin{array}{c}\text { Posterior } \\
(\mathrm{mm})\end{array}$ & $\begin{array}{c}\text { Degen- } \\
\text { eration } \\
\text { grade }\end{array}$ \\
\hline 1 & 73.5 & 40.9 & 14.4 & 1.3 & III \\
2 & 63.8 & 38.6 & 14.0 & 8.3 & IV \\
3 & 64.8 & 36.3 & 13.0 & 8.2 & II/III \\
4 & 60.9 & 37.8 & 12.1 & 2.2 & II/III \\
5 & 54.2 & 33.7 & 15.6 & 10.5 & IV \\
6 & 61.4 & 31.7 & 13.9 & 4.7 & IV \\
7 & 58.4 & 38.2 & 12.1 & 5.2 & II/III \\
8 & 72.3 & 43.0 & 19.6 & 2.6 & III \\
9 & 70.2 & 39.7 & 8.5 & 2.8 & IV \\
Mean (SD): & $64.3(6.5)$ & $37.7(3.5)$ & $13.7(2.9)$ & $5.1(3.2)$ & $3.3(0.71)$ \\
\hline
\end{tabular}

used to test the significance of mean differences in response measured with and without posterior elements.

\section{RESULTS}

The motions measured in response to the maximum loads applied to specimens with and without intact posterior elements are reported in terms of equivalent motions occurring at the center $(\mathrm{O})$ of the inferior endplate of the L5 vertebra $60 \mathrm{~s}$ after the load was applied. Eight of the nine motion segments showed no overt signs of tissue failure during testing with intact posterior elements.

\section{Shear and Compression Behavior}

For shear loads, the mean load displacement response of the intact specimens was linear (Fig. 2). At a load of $160 \mathrm{~N}$, the mean (SD) displacements in the direction of loading were as follows: anterior

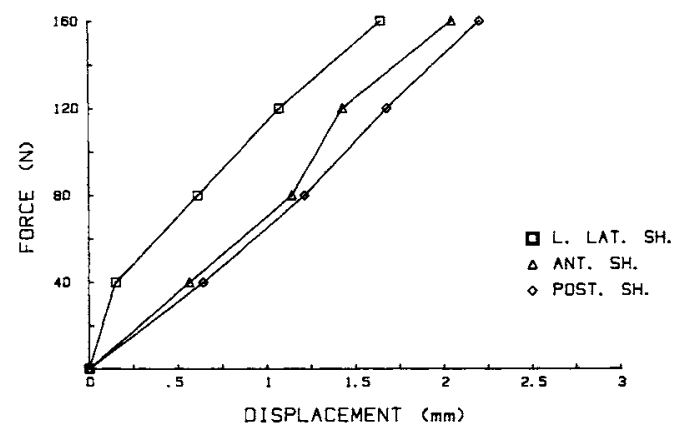

FIG. 2. Comparison of load displacement curves for the three shear loading directions (posterior elements intact). For clarity, bars indicating variability were omitted. See Table 2 for means and SD. All shear load displacement curves were linear, with the L5-S1 joint being stiffest in lateral shear and least stiff in posterior shear. shear resulted in a mean of $2.05 \mathrm{~mm}(1.39 \mathrm{~mm})$ and a range of 0.93-5.06 $\mathrm{mm}$, posterior shear resulted in a mean of $2.21 \mathrm{~mm}(0.87 \mathrm{~mm})$ and a range of $0.98-3.85 \mathrm{~mm}$, and left lateral shear resulted in a mean of $1.65 \mathrm{~mm}(0.63 \mathrm{~mm})$ and a range of $1.02-2.66 \mathrm{~mm}$. Thus, the segment was most stiff in lateral shear and least stiff in posterior shear, with mean displacements being $\leqslant 2 \mathrm{~mm}$. A compressive load of $320 \mathrm{~N}$ resulted in a mean displacement of $0.32 \mathrm{~mm}(0.16 \mathrm{~mm})$ and a range of $0.18-0.66 \mathrm{~mm}$.

The magnitude of displacements increased in the direction of loading when the posterior elements were removed. Specifically, at the $160 \mathrm{~N}$ load level, the mean anterior shear displacement increased $52 \%$ (Fig. 3), the mean posterior shear displacement increased $38 \%$, and the mean lateral shear displacement increased $23 \%$. The mean displacement in response to a $320 \mathrm{~N}$ compressive load increased $37 \%$.

\section{Bending and Torsional Behavior}

The load displacement response was nonlinear when moments were applied to the intact specimen, particularly in flexion (Fig. 4). At a maximum load of $15.7 \mathrm{Nm}$, mean (SD) rotations and ROM were as follows: flexion resulted in a mean of $7.19^{\circ}$ $\left(1.77^{\circ}\right)$ and a range of $4.68^{\circ}-10.01^{\circ}$, extension resulted in a mean of $5.16^{\circ}\left(1.28^{\circ}\right)$ and a range of $3.77^{\circ}-7.46^{\circ}$, and (right) lateral bending resulted in a mean of $4.38^{\circ}\left(1.44^{\circ}\right)$ and a range of $3.02-6.53^{\circ}$. An axial torque of $15.7 \mathrm{Nm}$ resulted in a mean (SD) axial torsion of $3.38^{\circ}\left(1.03^{\circ}\right)$ and a range of $2.00^{\circ}-$ $5.27^{\circ}$. Thus, the intact L5-S1 segment was stiffest in axial torsion and least stiff in flexion.

When the specimens were retested without posterior elements at the same loads, the magnitude of

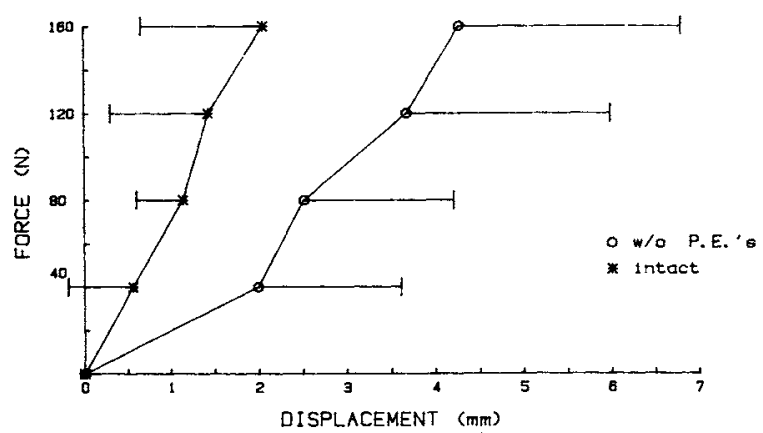

FIG. 3. Comparison of anterior shear load displacement response for intact motion segments $\left(^{*}\right)$ and for motion segments without posterior elements (o). Here and in Figs. 4 and 5 , horizontal bars indicate SD. 


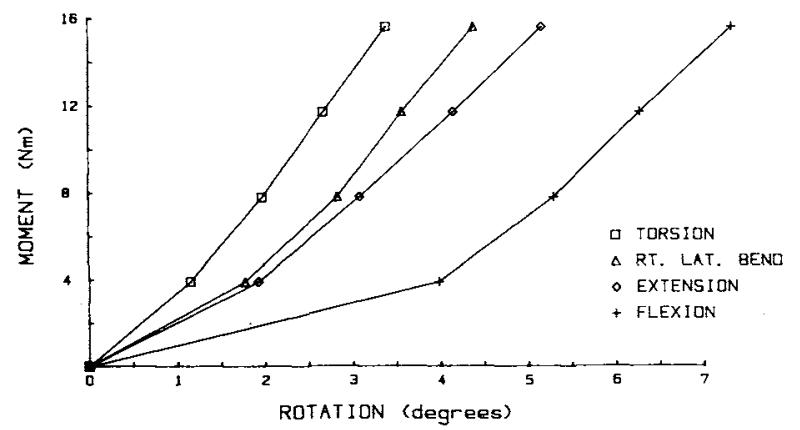

FIG. 4. Load displacement curves for bending and torsional loading of intact segments. For clarity, bars indicating variability were omitted. See Table 1 for means and SD.

rotations increased in all directions. The increase in rotation for flexion was 2.74 -fold, for extension it was 1.87 -fold, and for lateral bending it was 1.56 fold. The greatest increase, 2.74-fold, occurred in the torsion test (Fig. 5). Thus, without its posterior elements, the L5-S1 segment was no longer most stiff in torsion, but rather was most stiff in lateral bending and least stiff in flexion and extension.

\section{Coupled Motions}

A coupled motion of a point in a rigid body is one that occurs in a direction other than that of the applied load. For instance, when a lateral shear force is applied, the resulting lateral displacement is the main motion, but if torsion also occurs, torsion is a coupled motion. The translatory coupled motions of a point depend on its position relative to the instantaneous center of rotation. In intact specimens, coupled motions occurred in all test directions with the exception of compression, in which they were negligible. Table 3 summarizes the major coupled motion for each test direction.

In the shear tests, the largest coupled motions

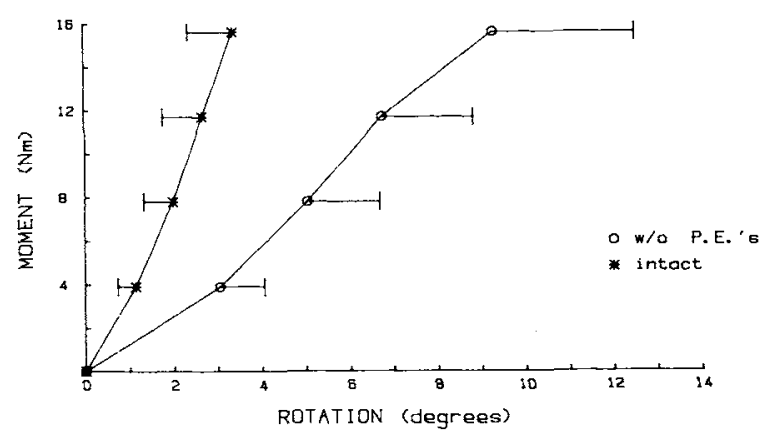

FIG. 5. Comparison of load displacement curves in counterclockwise torsion for intact motion segments $\left(^{*}\right)$ and for motion segments without posterior elements (o). were rotations. For a $160 \mathrm{~N}$ load, anterior shear resulted in a coupled flexion of mean (SD) $1.55^{\circ}$ $\left(1.07^{\circ}\right)$, posterior shear resulted in a coupled extension of $0.23^{\circ}\left(1.26^{\circ}\right)$, and lateral shear resulted in a coupled (left) lateral bending of $0.14^{\circ}\left(0.45^{\circ}\right)$. Large SDs were due principally to inconsistent signs of coupled displacements.

For a $15.7-\mathrm{Nm}$ test moment in bending, translations were the largest coupled motions. Flexion resulted in an anterior translation of $3.09 \mathrm{~mm}(1.69$ $\mathrm{mm}$ ), extension resulted in a posterior translation of $2.62 \mathrm{~mm}(0.83 \mathrm{~mm})$, and right lateral bending resulted in a right lateral translation of $2.72 \mathrm{~mm}(0.77$ $\mathrm{mm}$ ). For a $15.7-\mathrm{Nm}$ torsion test, the major coupled motion was a mean right lateral translation of 1.24 $\mathrm{mm}(0.91 \mathrm{~mm})$.

For specimens without posterior elements, coupled motions at the same reference loads were larger than for intact specimens (Table 3). Again, coupled motions for compressive loads were negligible. Anterior shear resulted in flexion of mean (SD) $3.12^{\circ}\left(2.11^{\circ}\right)$, posterior shear resulted in an extension of $0.11^{\circ}\left(1.63^{\circ}\right)$, and a left lateral shear resulted in a left lateral bend of $0.07^{\circ}\left(0.84^{\circ}\right)$. Major coupled motions in bending were as follows: Flexion resulted in an anterior displacement of mean $6.38 \mathrm{~mm}(2.13 \mathrm{~mm})$, extension resulted in a posterior displacement of $3.32 \mathrm{~mm}(1.77 \mathrm{~mm})$, and right lateral bending resulted in a right lateral displacement of $3.17 \mathrm{~mm}(1.01 \mathrm{~mm})$. In counterclockwise torsion without posterior elements, the major coupled motion was a right lateral displacement of $1.45 \mathrm{~mm}(1.16 \mathrm{~mm})$.

\section{Hysteresis and Creep}

Hysteresis was greatest in compression (34\%) and anterior shear (22\%) for intact specimens. When results for all directions were averaged, specimens with posterior elements intact showed slightly greater hysteresis $(18 \%)$ than that of specimens with posterior elements removed (12\%).

As an example of creep behavior, displacements $15 \mathrm{~s}$ after loading averaged $94(2) \%$ and $95(6) \%$ of the 60-s data in flexion and extension, respectively.

\section{Compressive Preload}

The effect of a compressive preload was studied in three specimens without posterior elements. One specimen was tested in torsion, and the remaining two were tested in lateral shear. With a $640-\mathrm{N}$ pre- 
TABLE 3. Coupled motions at maximum loads

\begin{tabular}{|c|c|c|c|c|c|}
\hline \multirow[b]{2}{*}{$\begin{array}{l}\text { Direction of } \\
\text { applied load }\end{array}$} & \multicolumn{2}{|c|}{ Posterior elements intact } & \multicolumn{2}{|c|}{ Without posterior elements } & \multirow{2}{*}{$\begin{array}{c}\text { Ratio: } \\
\text { without } \mathrm{PE} / \\
\mathrm{PE} \text { intact }\end{array}$} \\
\hline & Mean (SD) & $\begin{array}{l}\text { Coupled } \\
\text { motion }\end{array}$ & Mean (SD) & $\begin{array}{l}\text { Coupled } \\
\text { motion }\end{array}$ & \\
\hline Anterior shear & $1.55^{\circ}\left(1.07^{\circ}\right)$ & (flexion) & $3.12^{\circ}\left(2.11^{\circ}\right)$ & (flexion) & 2.01 \\
\hline Posterior shear & $0.23^{\circ}\left(1.26^{\circ}\right)$ & (extension) & $0.11^{\circ}\left(1.63^{\circ}\right)$ & (extension) & 0.50 \\
\hline $\begin{array}{l}\text { Left lateral } \\
\text { shear }\end{array}$ & $0.14^{\circ}\left(0.45^{\circ}\right)$ & Glotamol bond & & & \\
\hline Flexion & $3.09 \mathrm{~mm}(1.69 \mathrm{~mm})$ & $\begin{array}{l}\text { (lateral bend) } \\
\text { (anterior shear) }\end{array}$ & $6.38 \mathrm{~mm}(2.13 \mathrm{~mm})$ & $\begin{array}{l}\text { (lateral bend) } \\
\text { (anterior shear) }\end{array}$ & $\begin{array}{l}0.50 \\
2.06\end{array}$ \\
\hline Extension & $2.62 \mathrm{~mm}(0.83 \mathrm{~mm})$ & (posterior shear) & $3.32 \mathrm{~mm}(1.77 \mathrm{~mm})$ & (posterior shear) & 1.27 \\
\hline Right lateral & & & & & \\
\hline bend & $2.72 \mathrm{~mm}(0.77 \mathrm{~mm})$ & (lateral shear) & $3.17 \mathrm{~mm}(1.01 \mathrm{~mm})$ & (lateral shear) & 1.17 \\
\hline Torsion & $1.24 \mathrm{~mm}(0.91 \mathrm{~mm})$ & (lateral shear) & $1.45 \mathrm{~mm}(1.16 \mathrm{~mm})$ & (lateral shear) & 1.17 \\
\hline
\end{tabular}

$\mathrm{PE}$, posterior elements.

load, torsional rotation was reduced $27 \%$. In lateral shear at the maximum load, a $320-\mathrm{N}$ preload reduced lateral translation $27 \%$.

\section{Effect of Changing Point of Load Application}

Raising the point of load application $5.3 \mathrm{~cm}$ for a lateral shear test in two specimens without posterior elements increased lateral translation $48 \%$ and increased lateral rotation $73 \%$ due to the increased bending component.

\section{Stiffness Comparisons}

A comparison of secant and tangent stiffnesses over all test directions for intact specimens showed that the former averaged $13 \%$ less than the latter, and up to $40 \%$ less in flexion. With posterior elements removed, the corresponding values were 17 and $39 \%$, respectively.

\section{DISCUSSION}

To date, comprehensive data on the three-dimensional load displacement properties of the lumbosacral joint have not been published. Such data are important for analyses of the loads and motions occurring in the L5-S1 joint complex. They are also useful in understanding why pathologies at this level are more frequent than at other lumbar levels $(3,27)$.

How is the L5-S1 joint complex loaded in vivo? Due to gravitational and trunk muscle forces, the L3 level of the lumbar spine is typically loaded by compression loads ranging from $400 \mathrm{~N}$ to $1,647 \mathrm{~N}$ and shear loads up to $100 \mathrm{~N}$ (25). Therefore, the test loads used in this study seem of reasonable magnitude. For an average S1 inclination of $39^{\circ}$ (13), the load components parallel (anterior shear) and normal (axial compression) to the $S 1$ endplate amount to 63 and $78 \%$ of the vertical compression load. Thus, the L5-S1 joint is typically loaded by a shear component 0.81 times the axial compression component; the shear component can, however, range from 0.36 to fully 2.2 times the compression component over the full range of sacral endplate inclinations that occur in the standing position $\left(20^{\circ}-65^{\circ}\right)(13)$. In summary, given the magnitude of shear loading in vivo, it is not surprising that apart from torsion, anterior shear was the direction in which the L5-S1 posterior elements offered the most resistance to deformation (Table 1).

The magnitudes of the test loads used in this study $(160 \mathrm{~N}$ and $15.7 \mathrm{Nm})$ produced ROM in the L5-S1 joint similar to the maximum found in vivo. For example, in flexion and extension, Pearcy and co-workers $(20)$ found rotations of $9^{\circ}$ and $5^{\circ}$, respectively, whereas loads in the present study resulted in rotations of $7^{\circ}$ and $5^{\circ}$, respectively. Pearcy and Tibrewal (21) found maximal rotations of $2^{\circ}$ and $3^{\circ}$ in axial rotation and lateral bending, which correspond to $3^{\circ}$ and $4^{\circ}$ in the present study. Therefore, the magnitude of the present test loads appear to correlate reasonably well with those encountered in vivo.

\section{Effect of Posterior Element Excision}

The results in Table 1 demonstrate the important role played by the posterior elements in resisting loads applied to the motion segment. In all eight test directions, displacements were increased by posterior element excision; in five test directions, they were increased significantly. In the shear tests, 
average translations in the direction of the applied shear force increased 1.66-fold; bending rotations increased 2.09-fold, whereas in torsion the resulting rotation increased 2.74 -fold. These differences could actually be even greater in frontal plane test modes, since our mounting procedure required iliolumbar and intertransverse ligament excision.

\section{Coupled Motions}

Coupled motions were greater for specimens without posterior elements than for intact specimens in five of the eight loading directions. The exceptions were compression, in which coupled motions were negligible, and both posterior and lateral shear, in which there was little change in coupled motion when posterior elements were removed. In anterior shear, the coupled rotation (flexion) doubled after removal of the posterior elements. This was also true for flexion and its major coupled motion, anterior shear, thus agreeing with results of Berkson and colleagues (4) and Schultz and co-workers (24).

\section{Disc Degeneration}

All disc specimens included in this study exhibited some degeneration; five discs were grades II or III, and four were grade IV (most severe). The average degeneration level was grade 3 (Table 2); thus, this was a study of L5-S1 segments with degenerated discs. On the average, grade II discs appear in $\sim 10 \%$ of cadaver spines aged from $20-30$ years. In those aged between 40 and 50 years, $50 \%$ of the discs show grade III degeneration or more, whereas $<3 \%$ still have grade I discs (14).

\section{Resolution and Measurement Repeatability}

The resolution of the reported displacements was determined by multiplying the sensitivity of the least sensitive LVDT $(10.06 \mathrm{~mm} / \mathrm{V})$ by the sensitivity of the analog-to-digital conversion board $(0.04 \mathrm{~V} / \mathrm{bit})$ in the recording device. Thus, the reported displacements are resolved to $0.4 \mathrm{~mm}$. Resolution of the rotation measurements was determined by taking the arctangent of the quotient of the linear sensitivity $(0.4 \mathrm{~mm})$ and the distance separating the steel spheres on the upper fixture (100 $\mathrm{mm})$. Rotations were then resolved to $0.25^{\circ}$.

The average $\mathrm{SE}$ in anterior shear displacement measurements was $24 \%$ of the mean displacement in that direction. In torsion, the average $\mathrm{SE}$ was $2.8 \%$ of the mean rotation. The average error associated with linear extrapolation of results from the third load increment was $<+5 \%$. For nonlinear extrapolation, the error averaged $+9 \%$, which was deemed acceptable given the magnitude of interindividual variations.

\section{Effect of Methodology on Results}

The techniques and apparatus used in this study are similar to those used by Berkson and colleagues (4) and Schultz and co-workers (24). The major differences in the present study were (a) the use of electronic rather than mechanical measurement techniques, which resulted in synchronous displacement measurements; (b) the shear test loads being applied at the top surface of the disc; and (c) the absence of a $400-\mathrm{N}$ compressive preload. The second improvement eliminated the significant bending component associated with the more superior loading point used in the earlier shear studies. Although the presence of a preload is considered physiologic, the third improvement eliminated the bending component associated with an eccentrically located preload in shear, flexion-extension, and lateral bending tests, and minimized disc dehydration due to long-term compressive preloading (2).

We did, however, examine the effect of a compressive preload in two test directions. Torsion, with an increased stiffness of $27 \%$, was in agreement with the results of Panjabi and colleagues (19). The preload also increased stiffness in lateral shear, however, which is not in agreement with Panjabi's findings. This discrepancy can be explained by differences in the points of load application. In the present study, the shear loads were applied at the top surface of the intervertebral disc, resulting in the disc being placed in shear with little or no bending component. In the Panjabi study, the preload was applied several centimeters superiorly, introducing a moment component that tends to increase the apparent motions (see Results section, effect of changing point of load application).

\section{Stiffness Properties}

Table 4 is a comparison of the L5-S1 motion segment stiffnesses found in this study with reported stiffnesses for the more cranial L1-5 segments. Di- 
TABLE 4. Comparison of mean secant stiffness of intact specimens in direction of test load

\begin{tabular}{|c|c|c|c|c|c|c|c|}
\hline \multirow[b]{2}{*}{ Test direction } & \multirow[b]{2}{*}{ Berkson $^{a}$} & \multirow[b]{2}{*}{$\operatorname{Lin}^{b}$} & \multirow[b]{2}{*}{$\mathrm{Liu}^{c}$} & \multirow[b]{2}{*}{ Panjabi $^{d}$} & \multirow[b]{2}{*}{ Miller $^{e}$} & \multicolumn{2}{|c|}{ Present study $f$} \\
\hline & & & & & & With PE & Without PE \\
\hline Anterior shear & 145 & \multirow{2}{*}{294} & \multirow{2}{*}{384} & \multirow[t]{2}{*}{125} & 97 & $78(81)$ & $37(53)$ \\
\hline Posterior shear & 143 & & & & 140 & $72(77)$ & $45(52)$ \\
\hline Right lateral shear & 128 & 400 & 643 & 250 & 53 & $97(80)$ & $75(83)$ \\
\hline \multirow[t]{3}{*}{ Compression } & \multirow[t]{2}{*}{-} & \multirow[t]{2}{*}{-} & \multirow[t]{2}{*}{ - } & \multirow[t]{2}{*}{ - } & \multirow[t]{2}{*}{-} & $1,000(1,340)$ & $627(572)$ \\
\hline & & & & & & \multicolumn{2}{|c|}{ Present study ${ }^{k}$} \\
\hline & Schultz ${ }^{g}$ & \multicolumn{2}{|c|}{ Markolf ${ }^{h}$} & Panjabi ${ }^{i}$ & Miller ${ }^{j}$ & With PE & Without PE \\
\hline Flexion & 0.9 & \multicolumn{2}{|c|}{2.7} & 1.7 & 5.5 & $2.1(3.5)$ & $1.0(1.1)$ \\
\hline Extension & 2.2 & \multicolumn{2}{|c|}{3.6} & - & 7.6 & $3.0(3.6)$ & $1.4(2.3)$ \\
\hline Right lateral bend & 1.1 & \multicolumn{2}{|c|}{2.0} & 2.3 & 4.4 & $3.6(4.5)$ & $2.1(3.1)$ \\
\hline $\mathrm{CCW}$ torsion & 6.8 & \multicolumn{2}{|c|}{7.7} & 18.8 & 10.9 & $4.6(5.3)$ & $1.7(1.9)$ \\
\hline
\end{tabular}

(Mean tangent stiffness values are given in parentheses). Stiffness units are $\mathrm{N} / \mathrm{mm}$ (shear and compression tests) and $\mathrm{Nm} / \mathrm{degree}$ (bending and torsion tests).

${ }^{a}$ Data at $86-\mathrm{N}$ and $400-\mathrm{N}$ compressive preload, average degeneration grade 2.6 (4).

${ }^{b}$ Data at $100-\mathrm{N}$ and $440-\mathrm{N}$ compressive preload, average degeneration grade 2.3 (9).

c Data initial stiffness, no compressive preload (10).

${ }^{d}$ Data at $150 \mathrm{~N}$, no compressive preload (18).

$e$ Data at $980 \mathrm{~N}$, no compressive preload (12).

$f$ Data at $160 \mathrm{~N}$ (shear), $320 \mathrm{~N}$ (compression), no compressive preload, average degeneration grade 3.3.

8 Data at $4.7-\mathrm{Nm}$ and $400-\mathrm{N}$ compressive preload, average degeneration grade 2.6 (23).

${ }^{h}$ Data at $5.4 \mathrm{Nm}$, no compressive preload (11).

${ }^{i}$ Data at $7.5 \mathrm{Nm}$, no compressive preload (18).

$j$ Data at $68.6 \mathrm{Nm}$, no compressive preload (12).

${ }^{k}$ Data at $15.6 \mathrm{Nm}$, no compressive preload, average degeneration grade 3.3.

rect comparisons of other data sets with the present data (Table 4) are complicated by the fact that many of the studies were performed with: (a) a compressive preload of $400 \mathrm{~N}$, which can cause shear or bending stiffness underestimates; (b) different loading points, which can lead to a $48 \%$ underestimate of shear stiffness; (c) different kinematic restraints; and (d) stiffness definitions that sometimes include neutral zone behavior. Although the latter is true of the present secant stiffness, its effect was minimized by the use of an initial bias load (see Methods section). The tangent stiffness defined here circumvents this (included in Table 4 for comparison) but differs by $<13 \%$ from the secant data.

In the three shear tests, the intact L5-S1 joint had $0.50-0.75$ of the stiffness cited for joints at more cranial lumbar levels (Berkson and colleagues (4) data, Table 4). Due to different test methods this comparison may not be meaningful. In the three bending test directions, in which comparisons are more valid, the L5-S1 joint was from 1.36 to 3.27 times stiffer than the rest of the lumbar spine (data of Schultz and co-workers (24), Table 4). Posner and colleagues (22) also found L1-L2 and L3-L4 level segments to be significantly stiffer than the L5-S1 joint in flexion but not in extension. In tor- sion, we found the L5-S1 joint to be 1.47 times less stiff than the L1-L5 segments (data of Schultz and co-workers (24), Table 4), perhaps due to absence of the excised ilio-lumbar ligaments, but also due to the orientation of its L5-S1 facet joints. These joints are aligned $9^{\circ}(21 \%)$ further from the sagittal plane than at the L4-L5 level (5), an orientation that could be expected to result in reduced torsional resistance.

Acknowledgment: We gratefully acknowledge the support of Public Health Service (PHS) grants No. AM33948, AM36047, NS20535, and OH01962.

\section{REFERENCES}

1. Adams MA, Hutton WC: The effect of fatigue on the lumbar intervertebral disk. $J$ Bone Joint Surg (B) 65:199-203, 1983

2. Adams MA, Hutton WC: The effect of posture on the fluid content of the lumbar intervertebral disc. Spine 8:665-671, 1983

3. Anderson T: Frequency of prolapsus disci intervertebralis as cause of sciatica. Acta Med Scand 104:427-461, 1940

4. Berkson MH, Nachemson A, Schultz AB: Mechanical properties of human lumbar spine motion segments, Part II. $J$ Biomech Eng 101:53-57, 1979

5. Farfan HF: Mechanical Disorders of the Low Back. Philadelphia, Lea and Febiger, 1973, pp 34-35 
6. Hutton WC, Stott JRR, Cyron BM: Is spondylolysis a fatigue fracture? Spine 2:202-209, 1977

7. Keesson W, During J, Beeker W, Goudfrooij H, Crowe A: Recordings of the movement at the intervertebral segment L5-S1: A technique for the determination of the movement in the L5-S1 spinal segment by using three postural positions. Spine 9:83-90, 1984

8. Kelsey JL: Idiopathic low back pain: Magnitude of the problem. In: Symposium on Idiopathic Low Back Pain, ed by AA White III, SL Gordon, St. Louis, CV Mosby, 1982, pp 5-8

9. Lin HS, Liu YK, Adams KH: Mechanical response of the lumbar intervertebral joint under physiological (complex) loading. J Bone Joint Surg [AM] 60:41-55, 1978

10. Liu YK, Gautam R, Hirsh C: The resistance of the lumbar spine to direct shear. Orthop Clin North Am 6:33-48, 1975

11. Markolf KL: Deformation of the thoracolumbar intervertebral joints in response to external loads. J Bone Joint Surg $[A m]$ 54:511-533, 1971

12. Miller JAA, Schultz AB, Warwick DN, Spencer DL: Mechanical properties of lumbar spine motion segments under large loads. J Biomech 19:79-84, 1985

13. Miller JAA, Steen H, Skogland LB, Schultz AB: Sagittal geometry of the spine in females with and without idiopathic scoliosis. Spine (submitted for publication)

14. Miller JAA, Schmatz C, Schultz AB: Lumbar disc degeneration: correlation with age, sex and spine level in 600 autopsy specimens. $J$ Bone Joint Surg (submitted for publication)

15. Nachemson A: Lumbar intradiscal pressure. Experimental studies on post-mortem material. Acta Orth Scand (suppl 43) pp 41-43, 1960

16. Nachemson $A$ : The load on lumbar disks in different positions of the body. Clin Orthop 45:107-122, 1966

17. Panjabi MM, Krag MH, White AA, Southwick WO: Effects of preload on load-displacement curves of the lumbar spine. Orthop Clin North Am 8:181-192, 1977

18. Panjabi M, Krag MH, Chung TQ: Effects of disk injury on mechanical behavior of the human spine. Spine 9:707-713, 1984

19. Panjabi M, Summers DJ, Pelker RR, Videman $T$, Friedlander GW, Southwick WO: Three-dimensional load-displacement curves due to forces on the cervical spine. $J$ Orthop Res 4:152-161, 1986

20. Pearcy MJ, Portek J, Shepherd J: Three-dimensional x-ray analysis of normal movement in the lumbar spine. Spine 9:294-300, 1984

21. Pearcy MJ, Tibrewal SB: Axial rotation and lateral bending in the normal lumbar spine measured by three dimensiona radiography. Spine 9:582-587, 1984

22. Posner I, White AA, Edwards WT, Hayes WC: A biomechanical analysis of the clinical stability of the lumbar and lumbosacral spine. Spine 7:374-389, 1982

23. Schmorl G, Junghanns H: The Human Spine in Health and Disease, New York, Grune \& Stratton, 1971, p 88;172

24. Schultz AB, Warwick DN, Berkson MH, Nachemson A: Mechanical properties of human lumbar spine motion segments-Part I. J Biomech Eng 101:46-52, 1979

25. Schultz AB, Haderspeck K, Warwick DN, Portillo D: Use of lumbar trunk muscles in isometric performance of mechanically complex standing tasks. J Orthop Res 1:77-91, 1983

26. Snook SH: Low back pain in industry. In: Symposium on Idiopathic Low Back Pain, ed by AA White III, SL Gordon, St. Louis, CV Mosby, 1982, pp 23-38

27. Spangfort E: The lumbar disk herniation, a computer-aided analysis of 2504 operations. Acta Orthop Scand (suppl) 42:429-464, 1971

28. Troup JDG: Relation of lumbar spine disorders to heavy manual work and lifting. Lancet 1:857-861, 1965

29. Valkenberg HA, Haanen HCM: The epidemiology of low back pain. In: Symposium on Idiopathic Low Back Pain, ed by AA White III, SL Gordon, St. Louis, CV Mosby, 1982 , pp $9-22$

30. Wiltse LL, Winter RB: Terminology and measurement of spondolisthesis. $J$ Bone Joint Surg [Am] 65:768-772, 1983 